\title{
Relationship Between Bilirubin Concentration, Coronary Endothelial Function, and Inflammatory Stress in Overweight Patients
}

\author{
Satoshi Yoshino, Shuichi Hamasaki, Sanemasa Ishida, Tetsuro Kataoka, Akiko Yoshikawa, Naoya Oketani, \\ Keishi Saihara, Hideki Okui, Takuro Shinsato, Hitoshi Ichiki, Takuro Kubozono, So Kuwahata, Shoji Fujita, \\ Daisuke Kanda, Mitsuhiro Nakazaki, Masaaki Miyata, and Chuwa Tei
}

Department of Cardiovascular, Respiratory and Metabolic Medicine, Graduate School of Medicine, Kagoshima University, Kagoshima, Japan

\begin{abstract}
Aim: Bilirubin has antioxidant properties and may protect against atherosclerosis and coronary heart disease (CHD). Further, in patients with metabolic syndrome, hyperbilirubinemia is associated with attenuation of insulin resistance. The aim of the present study was to determine the relationship between serum bilirubin concentration and coronary endothelial function in overweight patients.

Methods: The study population consisted of 107 patients without CHD who underwent coronary flow studies. Vascular reactivity was examined by intra-coronary administration of papaverine and nitroglycerin. Coronary endothelial function was evaluated by assessing the change in coronary artery diameter to papaverine [percent change in flow-mediated dilatation (\%FMD)] and nitroglycerin (\%NTG). Serum total bilirubin, high-sensitivity C-reactive protein (hs-CRP), high density lipoprotein-cholesterol (HDL-C), fasting plasma glucose and immunoreactive insulin levels were also measured, and the homeostasis model assessment insulin resistance (HOMA-IR) index was calculated. Patients were divided into two groups according to body mass index (BMI): an overweight group (BMI $\geq 25 ; n=36$ ) and a normal weight group (BMI $<25 ; n=71$ ).

Results: In the overweight group, univariate analysis revealed that log-transformed total bilirubin was positively correlated with \%FMD and HDL-C $(r=0.38, p<0.05 ; r=0.30, p<0.05$, respectively $)$ and was inversely correlated with log-transformed hs-CRP and HOMA-IR $(r=-0.45, p<0.01 ; r=-0.45$, $p<0.05$, respectively). Multivariate analysis revealed that log-transformed hs-CRP was the only independent predictor of log-transformed total bilirubin $(p<0.05)$.

Conclusions: These results suggest that a high bilirubin level was associated with favorable coronary endothelial function in overweight patients. Further, the anti-inflammatory effects of bilirubin may mediate this effect.
\end{abstract}

J Atheroscler Thromb, 2011; 18:403-412.

Key words; Bilirubin, Endothelial dysfunction, Coronary artery, Inflammatory stress

\section{Introduction}

Bilirubin prevents the oxidation of low-density lipoprotein-cholesterol (LDL-C) ${ }^{1-3)}$, reduces the risk of atherosclerosis and coronary heart disease $(\mathrm{CHD})^{4-6)}$,

Address for correspondence: Shuichi Hamasaki, Department of Cardiovascular, Respiratory and Metabolic Medicine, Graduate School of Medicine, Kagoshima University, 8-35-1, Sakuragaoka, Kagoshima 890-8520, Japan

E-mail: hamasksh@m.kufm.kagoshima-u.ac.jp

Received: June 30, 2010

Accepted for publication: December 10, 2010 and attenuates insulin resistance in patients with metabolic syndrome ${ }^{7)}$. Further, low serum concentrations of bilirubin are associated with endothelial dysfunction $^{6)}$ and an increased risk of $\mathrm{CHD}^{8,9)}$ and metabolic syndrome ${ }^{10,11)}$.

Endothelial dysfunction is an early pivotal event in the development, progression, and manifestation of atherosclerosis $^{12,13)}$. Further, chronic systemic inflammation plays a major pathologic role in metabolic syndrome ${ }^{14)}$, and serum levels of inflammatory markers, including high-sensitivity C-reactive protein (hs-CRP), correlate with insulin resistance, endothelial dysfunc- 
tion and impaired fibrinolysis ${ }^{14-16)}$; however, the relationship among serum bilirubin, inflammatory markers, and coronary endothelial function remains unclear.

\section{Aim}

The aim of the present study was to determine the relationship between serum bilirubin concentration and coronary endothelial function and to identify the metabolic characteristics of participants that may modify the impact of serum bilirubin concentration on endothelial function.

\section{Methods}

\section{Study Population}

A total of 107 consecutive patients (age, 61 113 years), who had been referred to Kagoshima University Hospital for cardiac catheterization to exclude coronary artery disease from January 2000 to March 2008, were considered for enrollment in this study. Patients were divided into two groups according to body mass index $(\mathrm{BMI})^{15,16)}$ : an overweight group (BMI $\geq 25$; $n=36)$ and a normal weight group (BMI $<25 ; n=71)$. In this study, the overweight group contained pre-obese patients (BMI $\geq 25-<30)$ as well as obese patients $(\mathrm{BMI} \geq 30)^{17,18)}$.

Angiographic inclusion criteria were: 1) angiographically smooth arteries; 2) mild irregularities, $<30 \%$ lumen diameter stenosis by visual assessment in any major conduit vessel; and 3) proximal coronary arteries $>2.0 \mathrm{~mm}$ in diameter ${ }^{19)}$. Patients with a history of previous myocardial infarction, previous coronary revascularization, valvular heart disease, variant angina, cardiomyopathy, myocarditis, or high serum bilirubin concentration with liver dysfunction were excluded from this study.

Long-acting nitrates, calcium channel blocking agents, angiotensin-converting enzyme (ACE) inhibitors, angiotensin II receptor blockers (ARB), and $\beta$ adrenergic blockers were withheld for 48 hours before the study to allow for the assessment of baseline coronary physiology.

Written informed consent was obtained from all patients after the purpose, nature, and potential risks of the study were explained to the subjects in accordance with guidelines established by the Committee for the Protection of Human Subjects in our institution. Our institutional ethics committee reviewed and approved the study protocol.

\section{Study Protocol}

Diagnostic coronary angiography was performed using a 6F Judkins catheter with a standard femoral percutaneous approach. Five thousand units of heparin were administered at the beginning of the procedure. Non-ionic contrast material was used for all patients. No nitroglycerin was given prior to the diagnostic procedure.

Coronary artery response to papaverine and nitroglycerin was studied according to previous reports $^{20,21)}$. After control coronary angiograms, interventions were performed as follows: 1) a bolus of papaverine (an endothelium-independent vasodilator in resistance coronary arteries) $(12.5 \mathrm{mg} / 5 \mathrm{~mL})$ was injected through a catheter; 2) a bolus of nitroglycerin (an endothelium-independent vasodilator in conduit coronary arteries) $(200 \mu \mathrm{g} / 5 \mathrm{~mL})$ was administered. Drugs were infused at least 5 minutes apart. Coronary arteriography was performed before and 1 minute after injection of papaverine and after administration of nitroglycerin. Arterial blood pressure and heart rate were monitored continuously and recorded. Measurements obtained during steady state conditions were used as control values for later analysis.

\section{Assessment of Coronary Vasoreactivity}

Coronary endothelium-dependent function was evaluated by assessing the change in coronary artery diameter $(\mathrm{CAD})$ in response to papaverine [percent change in flow-mediated dilatation (\%FMD) ${ }^{22)}$. Endothelium-independent vasodilation of the conduit coronary artery was assessed by measuring the percent increase of $\mathrm{CAD}$ in response to nitroglycerin $(\% \mathrm{NTG})^{20,21)}$.

\section{Quantitative Coronary Angiographic Images}

Technically suitable single-plane angiograms were selected for computer analysis. Quantitative coronary angiographic images (DBAC-1000; MID Corporation, Fukuoka, Japan) were recorded using validated densitometric analysis, as previously reported ${ }^{23)}$. An end-diastolic still frame at each infusion (baseline, papaverine and nitroglycerin) was selected from the angiographic sequence. Endothelium-dependent and -independent vasodilation of the conduit coronary artery was estimated by measuring the luminal diameter. Measurements were performed by experienced observers who were unaware of the coronary vascular reactivity tests.

\section{Baseline Measurements and Biochemical Analysis}

A diagnosis of hypertension was based on systolic pressure $\geq 140 \mathrm{mmHg}$ and/or diastolic pressure $\geq 90$ $\mathrm{mmHg}$, or current treatment with antihypertensive 
Table 1. Comparison of patient characteristics between the two groups

\begin{tabular}{|c|c|c|c|}
\hline & $\begin{array}{l}\text { Overweight group } \\
\qquad(n=36)\end{array}$ & $\begin{array}{l}\text { Normal weight group } \\
\qquad(n=71)\end{array}$ & $p$ value \\
\hline Age, years & $60 \pm 12$ & $62 \pm 14$ & 0.616 \\
\hline BMI, $\mathrm{kg} / \mathrm{m}^{2}$ & $28.2 \pm 2.7$ & $21.9 \pm 1.9$ & $<0.001$ \\
\hline Systoic BP, mmHg & $136 \pm 21$ & $125 \pm 20$ & 0.004 \\
\hline Diastolic BP, mmHg & $80 \pm 14$ & $72 \pm 14$ & 0.006 \\
\hline Mean BP, mmHg & $99 \pm 15$ & $90 \pm 15$ & 0.003 \\
\hline Gender, male & $22(58 \%)$ & $45(62 \%)$ & 0.702 \\
\hline \multicolumn{4}{|l|}{ Risk factor } \\
\hline Diabetes mellitus & $9(25 \%)$ & $12(17 \%)$ & 0.326 \\
\hline Hypertension & $25(66 \%)$ & $36(50 \%)$ & 0.111 \\
\hline Dyslipidemia & $18(49 \%)$ & $21(29 \%)$ & 0.045 \\
\hline -High LDL-colesterol & $13(36 \%)$ & $11(16 \%)$ & 0.029 \\
\hline -Low HDL-cholesterol & $5(14 \%)$ & $7(11 \%)$ & 0.664 \\
\hline -Hypertriglycridemia & $10(28 \%)$ & $13(19 \%)$ & 0.334 \\
\hline Current smoking & $10(26 \%)$ & $25(34 \%)$ & 0.390 \\
\hline \multicolumn{4}{|l|}{ Drugs } \\
\hline Aspirin & $8(21 \%)$ & $26(36 \%)$ & 0.104 \\
\hline Calcium channel blocker & $17(45 \%)$ & $24(33 \%)$ & 0.222 \\
\hline ACE inhibitor & $6(16 \%)$ & $14(19 \%)$ & 0.659 \\
\hline $\mathrm{ARB}$ & $14(37 \%)$ & $23(32 \%)$ & 0.572 \\
\hline$\beta$-blocker & $7(21 \%)$ & $18(18 \%)$ & 0.679 \\
\hline Spironolactone & $2(5 \%)$ & $11(16 \%)$ & 0.096 \\
\hline Statin & $4(11 \%)$ & $9(13 \%)$ & 0.760 \\
\hline
\end{tabular}

Values are means \pm SDs or numbers of patients (percentages). BMI, body mass index; BP, blood pressure; ACE, angiotensin-converting enzyme; ARB, angiotensin II receptor blocker

drugs. Diabetes was defined on the basis of a fasting plasma glucose level $\geq 126 \mathrm{mg} / \mathrm{dL}$, HbA1c level $\geq 6.5 \%$, or the use of oral hypoglycemic agents or insulin. Dyslipidemia was defined on the basis of a fasting plasma LDL-C $\geq 140 \mathrm{mg} / \mathrm{dL}$, triglycerides $(\mathrm{TG}) \geq 150 \mathrm{mg} / \mathrm{dL}$, or active use of lipid-lowering medication. Cigarette smoking and the menstruation status were determined by self-reporting. BMI was calculated as weight in kilograms divided by the square of height in meters $\left(\mathrm{kg} / \mathrm{m}^{2}\right)^{17)}$.

Blood samples were obtained from subjects in the fasting state. Serum total bilirubin, direct bilirubin, LDL-C, high density lipoprotein-cholesterol (HDL-C) and TG values were measured using enzymatic methods (Roche Diagnostics Co., Ltd., Basel, Switzerland), implemented in an autoanalyzer (Modular Analytics, Roche Diagnostics Co., Ltd.). High- sensitivity CRP was measured by latex-enhanced nephelometry (Denka Seiken Co., Ltd., Tokyo, Japan). Fasting plasma glucose (FPG) was measured by the glucose oxidase method (GAO3U; A\&T Corp., Yokohama, Japan) ${ }^{24)}$. Immunoreactive insulin (IRI) was determined by a specific enzyme immunoassay with various reagents
(TOSOH Co., Ltd., Yamaguchi, Japan). HbA1C was assessed by the turbidimetric immunoassay method. Insulin resistance was evaluated by the homeostasis model assessment insulin resistance (HOMA-IR) index calculated as follows: FPG $(\mathrm{mg} / \mathrm{dL}) \times \mathrm{IRI}(\mu \mathrm{U} /$ $\mathrm{mL}) / 405^{25)}$.

\section{Statistical Analysis}

Statistical analysis was performed using Stat View Version 5.0 software. Values are expressed as the means \pm SDs. Before statistical analysis, normal distribution and homogeneity of the variances were tested. Parameters that did not fulfill these tests (total bilirubin, hs-CRP, TG, and HOMA-IR) were log transformed. Comparisons between the two groups were performed using Student's regression analysis unpaired $t$ test. Comparisons of risk factors and drugs between groups were performed using Pearson's chi-square test. All explanatory variables, including log-transformed total bilirubin, log-transformed hs-CRP, HDL-C, LDL-C, log-transformed TG, log-transformed HOMA-IR, mean blood pressure, age and BMI, were used as parameters for coronary vasoreactivity in both 
Table 2. Comparison of biochemical data between the two groups

\begin{tabular}{lccc}
\hline & $\begin{array}{c}\text { Overweight group } \\
(n=36)\end{array}$ & $\begin{array}{c}\text { Normal weight group } \\
(n=71)\end{array}$ & $p$ value \\
\hline T-bil, mg/dL & $0.7 \pm 0.2$ & $0.7 \pm 0.3$ & 0.613 \\
I-bil, mg/dL & $0.5 \pm 0.2$ & $0.5 \pm 0.2$ & 0.909 \\
hs-CRP, mg/dL & $0.35 \pm 0.66$ & $0.25 \pm 0.47$ & 0.378 \\
LDL-cholesterol, mg/dL & $129.6 \pm 34.5$ & $113.4 \pm 29.6$ & 0.019 \\
HDL-cholesterol, mg/dL & $53.1 \pm 12.5$ & $55.6 \pm 13.2$ & 0.360 \\
TG, mg/dL & $131.7 \pm 61.1$ & $121.8 \pm 72.1$ & 0.476 \\
FPG, mg/dL & $109.1 \pm 21.9$ & $104.3 \pm 25.3$ & 0.333 \\
IRI, $\mu$ U/mL & $10.0 \pm 11.5$ & $5.1 \pm 3.5$ & 0.018 \\
HbAlc, \% & $5.7 \pm 0.7$ & $5.6 \pm 1.2$ & 0.783 \\
HOMA-IR & $2.1 \pm 1.4$ & $1.3 \pm 0.9$ & 0.008 \\
\hline
\end{tabular}

Values are the means \pm SDs. T-bil, total bilirubin; I-bil, indirect bilirubin; hs-CRP, high-sensitivity C-reactive protein; LDL-cholesterol, low density lipoprotein cholesterol; HDL-cholesterol, high density lipoprotein cholesterol; TG, triglycerides; FPG, fasting plasma glucose; IRI, immunoreactive insulin; HOMA-IR, homeostasis model assessment ratio

Overweight group $(n=36)$

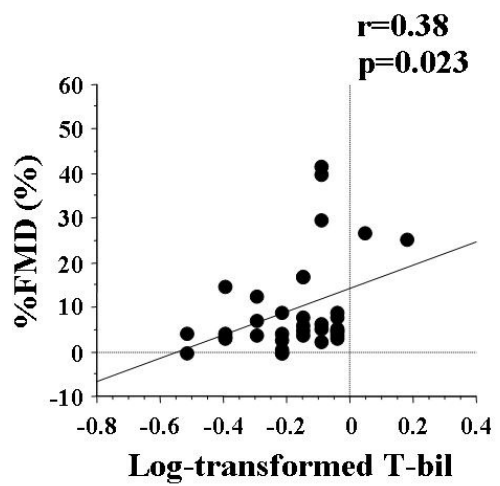

Normal weight group $(n=71)$

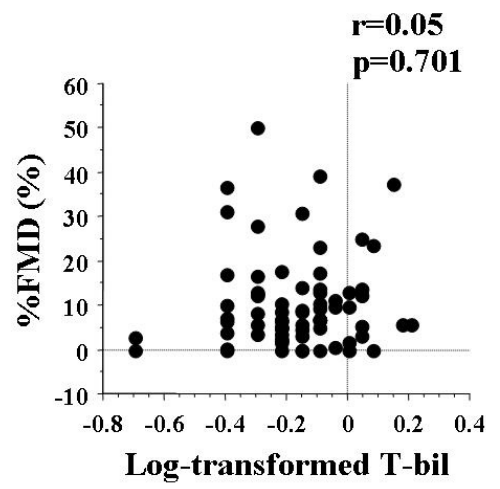

Fig. 1. Relationship between \%FMD and log-transformed T-bil.

FMD, flow-mediated dilatation; T-bil, total bilirubin

Pearson's correlation coefficient analysis and simple linear regression. Statistical analysis of parallelism in linear regression was employed to compare the slopes of the simple regression ${ }^{26)}$. Predictive factors for total bilirubin were determined using multiple regression analysis. A $p$ value $<0.05$ was considered significant.

\section{Results}

\section{Patient Characteristics}

A total of 107 patients were evaluated in this study. Patient characteristics are summarized in Table $\mathbf{1}$. Mean age was not significantly different when comparing the two groups. BMI, systolic, diastolic and mean blood pressures were significantly higher in the overweight group than in the normal weight group. Coronary risk factors were also similar when comparing the two groups, except for the prevalence of dyslipidemia, which was significantly higher in the overweight group than in the normal weight group. There was no significant difference between the two groups in the frequency of the use of cardiac medications.

Biochemical measurement characteristics are shown in Table 2. LDL-C, IRI and HOMA-IR were significantly higher in the overweight group than in the normal weight group.

\section{Relationship between Coronary Artery Reactivity and Total Bilirubin}

The relationship between \%FMD and total bili- 
Table 3. Correlation between $\% \mathrm{FMD}$ and risk factor variables in overweight patients

\begin{tabular}{lcc}
\hline \multirow{2}{*}{\multicolumn{1}{c}{ Parameters }} & \multicolumn{2}{c}{$\begin{array}{c}\text { Pearson's correlation } \\
\text { coefficient analysis }\end{array}$} \\
\cline { 2 - 3 } & $r$ value & $p$ value \\
\hline Log-transformed T-bil & 0.38 & 0.023 \\
Log-transformed hs-CRP & -0.14 & 0.444 \\
HDL-cholesterol & 0.01 & 0.979 \\
LDL-cholesterol & -0.06 & 0.759 \\
Log-transformed TG & 0.32 & 0.061 \\
Log-transformed HOMA-IR & 0.09 & 0.716 \\
Mean BP & 0.04 & 0.829 \\
Age & -0.23 & 0.177 \\
BMI & -0.14 & 0.427 \\
Gender, Male & -0.01 & 0.964 \\
\hline
\end{tabular}

T-bil, total bilirubin; hs-CRP, high-sensitivity C-reactive protein; HDL-cholesterol, high density lipoprotein cholesterol; LDL-cholesterol, low density lipoprotein cholesterol; TG, triglycerides; HOMA-IR, homeostasis model assessment ratio; BP, blood pressure; BMI, body mass index
Table 4. Correlation between \%FMD and risk factor variables in normal weight patients

\begin{tabular}{lcc}
\hline \multirow{2}{*}{\multicolumn{1}{c}{ Parameters }} & \multicolumn{2}{c}{$\begin{array}{c}\text { Pearson's correlation } \\
\text { coefficient analysis }\end{array}$} \\
\cline { 2 - 3 } & $r$ value & $p$ value \\
\hline Log-transformed T-bil & 0.05 & 0.701 \\
Log-transformed hs-CRP & 0.07 & 0.572 \\
HDL-cholesterol & -0.03 & 0.816 \\
LDL-cholesterol & -0.25 & 0.069 \\
Log-transformed TG & -0.07 & 0.570 \\
Log-transformed HOMA-IR & -0.02 & 0.884 \\
Mean BP & -0.07 & 0.556 \\
Age & -0.19 & 0.126 \\
BMI & 0.15 & 0.216 \\
Gender, Male & 0.11 & 0.350 \\
\hline
\end{tabular}

T-bil, total bilirubin; hs-CRP, high-sensitivity C-reactive protein; HDL-cholesterol, high density lipoprotein cholesterol; LDL-cholesterol, low density lipoprotein cholesterol; TG, triglycerides; HOMA-IR, homeostasis model assessment ratio; BP, blood pressure; BMI, body mass index
Overweight group $(n=36)$

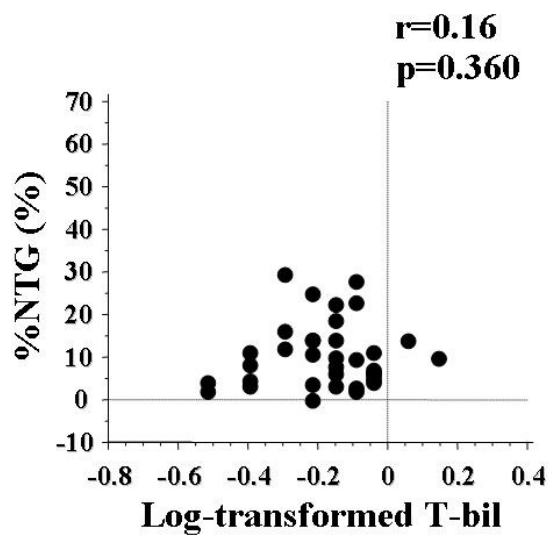

Normal weight group $(n=71)$

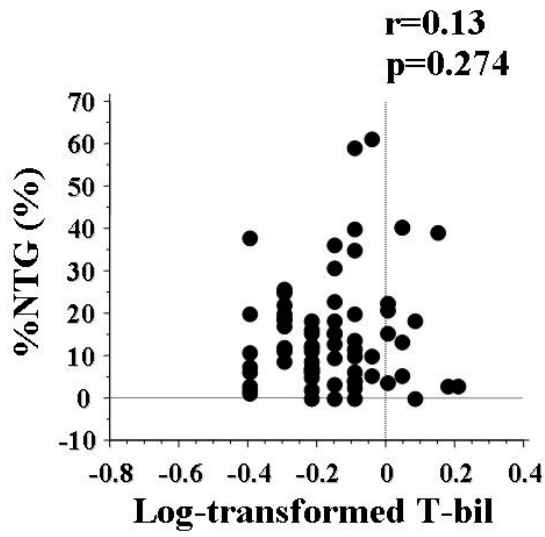

Fig. 2. Relationship between \%NTG and log-transformed T-bil.

NTG, endothelium-independent vasodilation induced by nitroglycerin; T-bil, total bilirubin

rubin is illustrated in Fig. 1. Univariate analysis revealed that \%FMD was positively correlated with $\log$-transformed total bilirubin in the overweight group $(r=0.38, p<0.05)$. By contrast, there was no correlation between \%FMD and total bilirubin in the normal weight group. The relationship between \%FMD and other risk factor variables in the overweight group is summarized in Table 3. \%FMD did not correlate with any variables other than the bilirubin level. The relationship between \%FMD and other risk factor variables in the normal weight group is presented in Table 4. \%FMD did not correlate with any variables. $\%$ NTG was not significantly correlated with total bilirubin in the overweight or normal weight group (Fig. 2). In the overweight group, we also compared \%FMD and \%NTG based on the value of logtransformed total bilirubin [lower bilirubin patients (log-transformed total bilirubin $<-0.18, n=15$ ); higher bilirubin patients (log-transformed total bilirubin $\geq-0.18, n=21)]$. \%FMD was significantly lower 
A

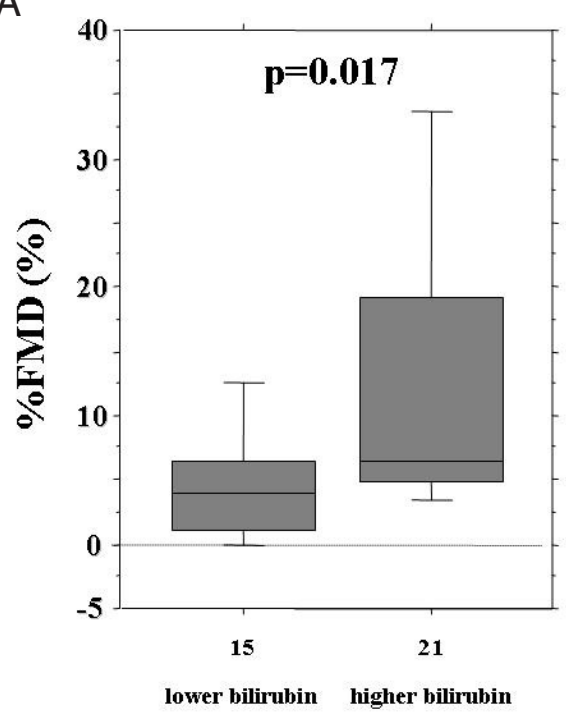

B

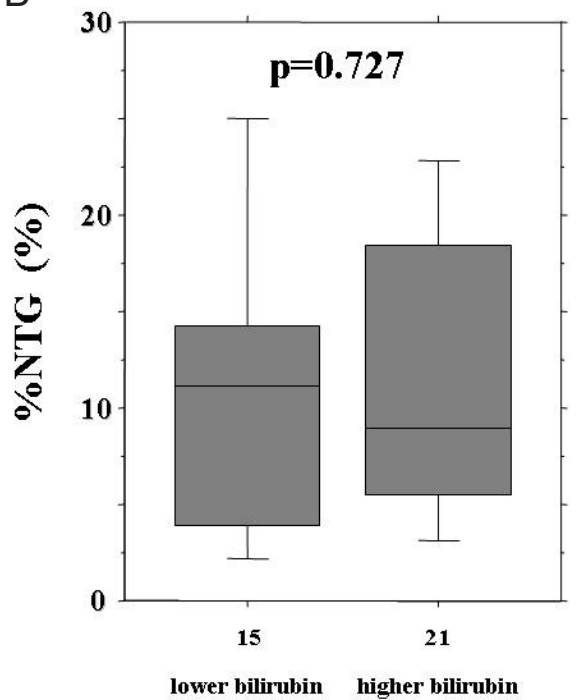

Fig. 3. (A) Box plots of \%FMD values in lower and higher bilirubin groups. (B) Box plots of $\%$ NTG values in lower and higher bilirubin groups.

FMD, flow-mediated dilatation; NTG, endothelium-independent vasodilation induced by nitroglycerin; horizontal lines of the box represent median; boxed area is the interquartile range; vertical whiskers represent the $10-90 \%$ range.

in the lower bilirubin group than in the higher bilirubin group $(4.6 \pm 4.5 \%$ vs. $13.0 \pm 12.4 \% ; p<0.05)$. By contrast, there was no significant difference in \%NTG when comparing the lower and higher bilirubin groups (10.7 $\pm 8.4 \%$ vs. $11.3 \pm 7.7 \%$; $p=0.83)$ (Fig. 3). These results suggest that coronary endothelial function was impaired in overweight patients with lower bilirubin levels. Furthermore, \%FMD in overweight patients with higher bilirubin levels was comparable to $\%$ FMD in normal weight patients, irrespective of whether they had lower or higher bilirubin levels (13.0 $\pm 12.4 \%$ vs. $10.3 \pm 11.4 \%$ and $10.7 \pm 9.9 \%$, respectively; $p=\mathrm{NS}$ ).

\section{Parameters Contributing to Total Bilirubin}

In the overweight group, log-transformed total bilirubin was positively correlated with HDL-C $(r=0.30, p<0.05)$ and was inversely correlated with log-transformed hs-CRP and log-transformed HOMA-IR $(r=-0.45, p<0.01 ; r=-0.45, p<0.05$, respectively) (Table 5). Log-transformed total bilirubin did not correlate with LDL-C, log-transformed TG, mean BP, age, BMI, or gender (Table 5).

In the normal weight group, log-transformed total bilirubin was inversely correlated with $\log$ transformed HOMA-IR and age $(r=-0.40, p<0.01$; $r=-0.26, p<0.05$, respectively) (Table 6). Although there was an inverse correlation between total biliru- bin and HOMA-IR in both groups, there was no significant difference in the regression coefficient when comparing the groups $(p=0.29)$. In addition, logtransformed total bilirubin did not correlate with logtransformed hs-CRP, HDL-C, LDL-C, log-transformed TG, mean BP, BMI, or gender (Table 6).

Multivariate analysis revealed that log-transformed hs-CRP was the only independent predictor of log-transformed total bilirubin in the overweight group $(p<0.05)$ (Table 5). By contrast, no predictor of log-transformed total bilirubin was identified in the normal weight group (Table 6).

Further, we compared hs-CRP between the lower and higher bilirubin groups in the overweight and normal weight groups. In the overweight group, hs-CRP was significantly higher in the lower bilirubin group than in the higher bilirubin group $(0.56 \pm 0.86$ $\mathrm{mg} / \mathrm{dL}$ vs. $0.12 \pm 0.12 \mathrm{mg} / \mathrm{dL} ; p<0.05)$.

\section{Discussion}

The present study demonstrated that \%FMD was positively correlated with log-transformed total bilirubin in the overweight group but not in the normal weight group, suggesting that elevated bilirubin levels are associated with favorable coronary artery endothelial function in overweight patients. \%FMD did not correlate with any risk factor variables other 
Table 5. Predictive factors for total bilirubin in overweight patients

\begin{tabular}{|c|c|c|c|}
\hline \multirow{2}{*}{ Parameters } & \multicolumn{2}{|c|}{$\begin{array}{l}\text { Pearson's correlation } \\
\text { coefficient analysis }\end{array}$} & \multirow{2}{*}{$\begin{array}{c}\begin{array}{c}\text { Multiple regression } \\
\text { analysis }\end{array} \\
p \text { value }\end{array}$} \\
\hline & $r$ value & $p$ value & \\
\hline Log-transformed hs-CRP & -0.45 & 0.002 & 0.048 \\
\hline HDL-cholesterol & 0.30 & 0.048 & 0.464 \\
\hline LDL-cholesterol & 0.01 & 0.982 & 0.659 \\
\hline Log-transformed TG & 0.20 & 0.189 & 0.099 \\
\hline Log-transformed HOMA-IR & -0.44 & 0.041 & 0.265 \\
\hline Mean BP & 0.01 & 0.945 & 0.876 \\
\hline Age & 0.08 & 0.580 & 0.649 \\
\hline BMI & -0.03 & 0.849 & 0.203 \\
\hline Gender, Male & 0.12 & 0.415 & 0.223 \\
\hline
\end{tabular}

hs-CRP, high-sensitivity C-reactive protein; HDL-cholesterol, high density lipoprotein cholesterol; LDLcholesterol, low density lipoprotein cholesterol; TG, triglycerides; HOMA-IR, homeostasis model assessment ratio; BP, blood pressure; BMI, body mass index

Table 6. Predictive factors for total bilirubin in normal weight patients

\begin{tabular}{|c|c|c|c|}
\hline \multirow{2}{*}{ Parameters } & \multicolumn{2}{|c|}{$\begin{array}{l}\text { Pearson's correlation } \\
\text { coefficient analysis }\end{array}$} & \multirow{2}{*}{$\begin{array}{c}\begin{array}{c}\text { Multiple regression } \\
\text { analysis }\end{array} \\
p \text { value }\end{array}$} \\
\hline & $r$ value & $p$ value & \\
\hline Log-transformed hs-CRP & -0.18 & 0.114 & 0.293 \\
\hline HDL-cholesterol & 0.22 & 0.063 & 0.491 \\
\hline LDL-cholesterol & 0.06 & 0.591 & 0.284 \\
\hline Log-transformed TG & 0.10 & 0.385 & 0.265 \\
\hline Log-transformed HOMA-IR & -0.40 & 0.001 & 0.107 \\
\hline Mean BP & 0.03 & 0.797 & 0.534 \\
\hline Age & -0.26 & 0.018 & 0.131 \\
\hline BMI & 0.14 & 0.196 & 0.638 \\
\hline Gender, Male & 0.13 & 0.209 & 0.246 \\
\hline
\end{tabular}

hs-CRP, high-sensitivity C-reactive protein; HDL-cholesterol, high density lipoprotein cholesterol; LDLcholesterol, low density lipoprotein cholesterol; TG, triglycerides; HOMA-IR, homeostasis model assessment ratio; BP, blood pressure; BMI, body mass index

than bilirubin. Furthermore, log-transformed total bilirubin was significantly correlated with log-transformed hs-CRP, HOMA-IR, and HDL-C. Among these parameters, hs-CRP was the only independent factor that correlated with total bilirubin.

Several studies have noted an inverse relationship between the presence of CHD and total bilirubin. Hopkins et al. ${ }^{5}$ ) showed that higher serum bilirubin is associated with a decreased risk for CHD. This reduction was independent of other known CHD risk and covariates. The apparent protective effects of bilirubin were of a similar magnitude as HDL-C. Schwertner $e t$ al. ${ }^{8)}$ indicated that low bilirubin concentration is associated with the presence of CHD. These and other investigators found that plasma bilirubin correlated inversely with several known risk factors for $\mathrm{CHD}$, such as smoking, LDL-C, diabetes and obesity, and correlated directly with HDL-C ${ }^{27,28)}$.

\section{Relationship between Coronary Endothelial Func- tion and Total Bilirubin}

Erdogan et al. ${ }^{6}$ ) used analysis of forearm blood flow by strain-gauge plethysmography to demonstrate that serum total bilirubin was independently related to the vasodilator response to reactive hyperemia. Anderson et al. ${ }^{29)}$ suggested that endothelial dysfunction in the brachial artery correlated with coronary endothelial dysfunction. Their reports did not indicate whether the correlation between serum total bilirubin and endothelial function was similar when comparing 
coronary and peripheral arteries. Further, although the brachial artery does develop atherosclerosis ${ }^{30)}$, it is clinically different from the occlusive disease that affects the coronary circulation. For these reasons, our study was designed to investigate the more specific association between serum total bilirubin and \%FMD in the coronary artery.

In this study, \%FMD correlated with total bilirubin only in overweight patients, and \%FMD was significantly lower in the lower than higher bilirubin group in overweight patients. Moreover, \%FMD in overweight patients with higher total bilirubin was comparable to that in normal weight patients irrespective of total bilirubin. These results show that bilirubin may be protective against atherosclerosis in overweight patients, possibly via the promotion of endothelial function.

Several studies have documented that exposure to oxidative stress is greater in overweight patients than normal weight patients, which means that coronary endothelial function may be more easily impaired in overweight patients ${ }^{31,32)}$; however, data from the present study suggest that high bilirubin levels may be protective against coronary endothelial dysfunction in overweight patients, although the same effect may not hold true in normal weight patients.

\section{Relationship between Total Bilirubin and Metabolic Syndrome}

In our study, serum total bilirubin was inversely associated with HOMA-IR in both weight groups. There was no significant difference in the regression coefficient when comparing the two groups.

Previous studies, ${ }^{73}$ ) demonstrated that serum total bilirubin was inversely associated with insulin resistance in children and adolescents with metabolic syndrome and in young adults, possibly via its anti-oxidative effect or via the effect of its metabolic pathway (biliverdin reductase cycle) on insulin signaling ${ }^{34-36)}$. Giral et al. ${ }^{37)}$. demonstrated that patients with metabolic syndrome had a lower level of serum bilirubin that patients without metabolic syndrome. Our data showed no significant difference in total bilirubin between overweight and normal weight patients. By contrast, BMI, prevalence of hypertension, LDL-C, IRI, and HOMA-IR were significantly higher in overweight than normal weight patients, which would be expected to adversely impact coronary endothelial function in overweight patients. As mentioned previously, our data also showed that a higher level of total bilirubin in overweight patients could protect against impairment of coronary endothelial function. Thus, the relationship between total bilirubin and endothelial function may be more prominent in overweight patients.

\section{Relationship between Total Bilirubin and HDL- Cholesterol}

Our study showed a positive correlation between total bilirubin and HDL-C in overweight patients.

Vitek et al. ${ }^{38)}$ reported that bilirubin, total antioxidant capacity and HDL-C were significantly higher in subjects with Gilbert syndrome than in control groups. In addition, Bhuiyan et al. ${ }^{31)}$ observed that the bilirubin level was positively associated with HDL-C in young adults. Another study suggested that the protective effect of bilirubin on CHD risk is comparable to that of HDL-C ${ }^{8)}$. In line with its antioxidant properties, it is tempting to speculate that elevated bilirubin levels might protect LDL apoproteins and lipids from being oxidized, thus reducing the catabolic rate mediated by HDL receptor ${ }^{39)}$. Thus, it is possible that the beneficial effects of bilirubin are additive or synergistic to those of HDL-C in overweight patients.

\section{Relationship between Total Bilirubin and hs-CRP}

Oxidized LDL-C is produced in arteriosclerotic lesions and compromises vascular endothelial function $^{40)}$. HDL-C can protect LDL-C against oxidation $^{39)}$, and hs-CRP is a sensitive marker of chronic inflammation occurring in arteriosclerotic lesions ${ }^{41)}$. In addition, hs-CRP is an independent predictor of future cardiovascular events ${ }^{42)}$.

Our study demonstrated that total bilirubin was inversely correlated with hs-CRP in overweight patients. Furthermore, hs-CRP in overweight patients with lower total bilirubin was significantly higher than that in overweight patients with higher total bilirubin. These results suggest that higher bilirubin levels may contribute to an anti-inflammatory effect in overweight patients.

Several studies have described the relationship between CRP and total bilirubin. Tapan et al. ${ }^{43)}$ showed that hs-CRP was negatively correlated with total bilirubin in patients with Gilbert's syndrome. Yang et al. ${ }^{44)}$ established that hypertensive patients with carotid atherosclerosis had lower serum bilirubin and higher CRP than hypertensive patients without carotid atherosclerosis. Gonzalez et al. ${ }^{45)}$ showed that endothelial dysfunction and inflammation (increased CRP) were important indicators of vascular risk in patients with metabolic syndrome. In this context, the beneficial effects of bilirubin may be mediated by its anti-inflammatory effect in overweight patients.

\section{Clinical Implications}

The present study described the relationship 
between coronary endothelial function and total bilirubin and demonstrated an independent correlation between total bilirubin and hs-CRP. These data suggest that high bilirubin is associated with favorable coronary endothelial function and a lower risk of $\mathrm{CHD}$, possibly via the anti-inflammatory effect of bilirubin in overweight patients without overt coronary atherosclerotic lesions. Thus, bilirubin may provide a new marker for the assessment of atherogenic risk as well as a therapeutic target for the modification of atherogenic risk. Indeed, several groups of investigators have demonstrated that weight loss therapy (either by sibutramine or via placement of an intragastric balloon) is associated with a rapid increase in total bilirubin levels and antioxidant capacity ${ }^{46,47)}$.

\section{Limitations}

This study has several limitations. First, our measurements were based on a single determination of total bilirubin concentration, and the time course relationship with vascular events cannot be predicted from the current study. Additionally, the methodology for coronary angiography and selective intra-coronary infusion used in this study is not amenable to establishing causality through repeat examinations. Second, the present study is cross-sectional, and its findings warrant confirmation through a prospective study. Third, because of the relatively small number of participants in our study population, further investigation involving a large number of patients with adjustment for confounding factors, such as gender or menopausal status, is required to confirm the clinical utility of total bilirubin as a marker of coronary endothelial function. Finally, the study population included only patients with normal or mildly diseased coronary arteries. Thus, the present findings may not be applicable to patients with advanced CHD.

\section{Conclusions}

This in vivo study demonstrated that high bilirubin was associated with favorable coronary endothelial function in overweight patients. Further, the anti-inflammatory effects of bilirubin may mediate this effect.

\section{References}

1) Stocker R, Yamamoto Y, McDonagh AF, Glazer AN, Ames BN: Bilirubin is an antioxidant of possible physiological importance. Science, 1987; 235: 1043-1046

2) Stocker R, Ames BN: Potential role of conjugated bilirubin and copper in the metabolism of lipid peroxides in bile. Proc Natl Acad Sci, 1987; 84: 8130-8134

3) Wu TW, Fung KP, Wu J, Yang CC, Weisel RD: Antioxi- dation of human low density lipoprotein by unconjugated and conjugated bilirubins. Biochem Pharmacol, 1996; 51 : 859-862

4) Djusse L, Levy D, Cupples LA, Evans JC, D'Agostino $\mathrm{RB}$, Ellison RC: Total serum bilirubin and risk of cardiovascular disease in the Framingham offspring study. Am J Cardiol, 2001; 87: 1196-1200

5) Hopkins PN, Wu LL, Hunt SC, James BC, Vincent GM, Williams RR: Higher serum bilirubin is associated with decreased risk for early familial coronary artery disease. Arterioscler Thromb Vasc Biol, 1996; 16: 250-255

6) Erdogan D, Gullu H, Yildrim E, Tok D, Kirbas I, Ciftci O, Baycan ST, Muderrisoglu Het: Low serum bilirubin levels are independently and inversely related to impaired flowmediated vasodilatation and increased carotid intimamedia thickness in both men and women. Atherosclerosis, 2006; 184: 431-437

7) Lin LY, Kuo HK, Hwang JJ, Lai LP, Chiang FT, Tseng CD, Lin JL: Serum bilirubin is inversely associated with insulin resistance and metabolic syndrome among children and adolescents. Atherosclerosis, 2009; 203: 563-568

8) Schwertner HA, Jackson WG, Tolan G: Asscoation of low serum bilirubin with increased risk of coronary artery disease. Clin Chem, 1994; 40: 18-23

9) Breimer LH, Wannamethee G, Ebrahim S, Shaper AG: Serum bilirubin and risk of ischemic heart disease in middle-aged men. Clin Chem, 1995; 41: 1504-1508

10) Torgerson JS, Lindroos AK, Sjostrom CD, Olsson R, Lissner L, Sjöström L: Are elevated aminotransferases and decreased bilirubin additional characteristics of the metabolic syndrome? Obes Res, 1997; 5: 105-114

11) Ishizaka N, Ishizaka $Y$, Toda E, Nagai R, Yamamoto $M$ : Association between serum uric acid, metabolic syndrome, and carotid atherosclerosis in Japanese individuals. Arterioscler Thromb Vasc Biol, 2005; 25: 1038-1044

12) Davignon J, Ganz P: Role of endothelial dysfunction in atherosclerosis. Circulation, 2004; 109: III 27-32

13) Vanhoutte PM: The endothelium-modulator of vascular smooth-muscle tone. N Engl J Med, 1988; 319: 512-513

14) Ridker PM: Clinical application of C-reactive protein for cardiovascular disease detection and prevention. Circulation, 2003; 107: 363-369

15) Hirose H, Kawabe H, Komiya N, Saito I: Relations between serum reactive oxygen metabolites (ROMs) and various inflammatory and metabolic parameters in a Japanese population. J Atheroscler Thromb, 2009; 16: 77-82

16) Corrado E, Rizzo M, Coppola G, Fattouch K, Novo G, Marturana I, Ferrara F, Novo S: An update on the role of markers of inflammation in atherosclerosis. J Atheroscler Thromb, 2010; 17: 1-11

17) WHO/IASO/IOTF: The Asia-Pacific perspective: redefining obesity and its treatment. Health communications Australia Pty Ltd, 2000

18) Janssen I, Katzmarzyk PT, Boyce WF, Vereecken C, Mulvihill C, Roberts C, Currie C, Pickett W; Health Behaviour in School-Aged Children Obesity Working Group: Comparison of overweight and obesity prevalence in school-aged youth from 34 countries and their relationship with physical activity and dietary patterns. Obes Rev, 2005; 6: 123-132 
19) Suwaidi JA, Hamasaki S, Higano ST, Nishimura RA, Holmes DR Jr, Lerman A: Long-term follow-up of patients with mild coronary artery disease and endothelial dysfunction. Circulation, 2000; 101: 948-954

20) Hasdai D, Gibbons RJ, Holmes DR Jr, Higano ST, Lerman A: Coronary endothelial dysfunction in humans is associated with myocardial perfusion defects. Circulation, 1997; 96: 3390-3395

21) Suwaidi JA, Higano ST, Holmes DR Jr, Lennon R, Lerman A: Obesity is independently associated with coronary endothelial dysfunction in patients with normal or mildly diseased coronary arteries. J Am Coll Cardiol, 2001; 37: 1523-1528

22) Schachinger V, Britten MB, Zeiher AM: Prognostic impact of coronary vasodilator dysfunction on adverse long-term outcome of coronary heart disease. Circulation, 2000; 101: 1899-1906

23) Kataoka T, Hamasaki S, Ishida S, Saihara K, Okui H, Fukudome T, Shinsato T, Mizoguchi E, Ninomiya Y, Otsuji Y, Minagoe S, Tei C: Contribution of increased minimal coronary resistance and attenuated vascular adaptive remodeling to myocardial ischemia in patients with systemic hypertension and ventricular hypertrophy. Am J Cardiol, 2004; 94: 484-487

24) Huggett AS, Nixon DA: Use of glucose oxidase, peroxidase and O-dianisidine in determination of blood and urinary glucose. Lancet, 1957; 273: 368-370

25) Matthews DR, Hosker JP, Rudenski AS, Naylor BA, Treacher DF, Turner RC: Homeostasis model assessment: insulin resistance and beta-cell function from fasting plasma glucose and insulin concentrations in man. Diabetologia, 1985; 28: 412-419

26) Zar JH: Biostatistical analysis 2nd ed., Englewood Cliff Prentice-Hall, NJ, 1984

27) Schwertner HA: Association of smoking and low serum bilirubin antioxidant concentrations. Atherosclerosis, 1998; 136: 383-387

28) Madhavan M, Wattigney WA, Srinivasan SR, Berenson GS: Serum bilirubin distribution and its relation to cardiovascular risk in children and young adults. Atherosclerosis, 1997; 131: 107-113

29) Anderson TJ, Uehata A, Gerhard MD, Meredith IT, Knab S, Delagrange D, Lieberman EH, Ganz P, Creager MA, Yeung AC, Selwyn AP: Close relation of endothelial function in human coronary and peripheral circulations. J Am Coll Cardiol, 1995; 26: 1235-1241

30) Sorensen KE, Kristensen IB, Celermajer DS: Atherosclerosis in the human brachial artery. J Am Coll Cardiol, 1997; 29: 318-322

31) Galili O, Versari D, Sattler KJ, Olson ML, Mannheim D, McConnell JP, Chade AR, Lerman LO, Lerman A: Early experimental obesity is associated with coronary endothelial dysfunction and oxidative stress. Am J Physiol Heart Circ Physiol, 2007; 292: H904-911

32) Grassi G, Seravalle G, Scopelliti F, Dell'Oro R, Fattori L, Quarti-Trevano F, Brambilla G, Schiffrin EL, Mancia G: Structural and functional alterations of subcutaneous small resistance arteries in severe human obesity. Obesity, 2010;18: 92-98

33) Bhuiyan AR, Srinivasan SR, Chen W, Sultana A, Beren- son GS: Association of serum bilirubin with pulsatile arterial function in asymptomatic young adults: the Bogalusa Heart Study. Metabolism, 2008; 57: 612-616

34) Sedlak TW, Snyder SH: Bilirubin benefits: cellular protection by a biliverdin reductase oxidant cycle. Pediatrics, 2004; 113: 1776-1782

35) Maines MD: New insights into biliverdin reductase functions: linking heme metabolism to cell signaling. Physiology, 2005; 20: 382-389

36) Maines MD: Biliverdin reductase: PKC interaction at the cross-talk of MAPK and PI3K signaling pathways. Antioxid Redox Signal, 2007; 12: 2187-2195

37) Giral P, Ratziu V, Couvert P, Carrié A, Kontush A, Girerd $\mathrm{X}$, Chapman MJ: Plasma bilirubin and gamma-glutamyltransferase activity are inversely related in dyslipidemic patients with metabolic syndrome: relevance to oxidative stress. Atherosclerosis, 2010; 210: 607-613

38) Vítek L, Jirsa M, Brodanová M, Kaláb M, Marecek Z, Danzig V, Novotny L, Kotal P: Gilbert syndrome and ischemic heart disease: a protective effect of elevated bilirubin levels. Atherosclerosis, 2002; 160: 449-456

39) Fluiter K, Sattler W, De Beer MC, Connell PM, van der Westhuyzen DR, van Berkel TJ: Scavenger receptor BI mediates the selective uptake of oxidized cholesterol esters by rat liver. J Biol Chem, 1999; 274: 8893-8899

40) Crisby M, Kublickiene K, Henareh L, Agewall S: Circulating levels of autoantibodies to oxidized low-density lipoprotein and C-reactive protein levels correlate with endothelial function in resistance arteries in men with coronary heart disease. Heart Vessels, 2009; 24: 90-95

41) Tokac M, Ozen A, Aktan M, Altunkeser BB, Ozdemir K, Duzenli A, Gok H: The role of inflammation markers in triggering acute coronary events. Heart Vessels, 2003; 18 : 171-176

42) Ridker PM: C-reactive protein and the prediction of cardiovascular events among those at intermediate risk: moving an inflammatory hypothesis toward consensus. J Am Coll Cardiol, 2007; 49: 2129-2138

43) Tapan S, Dogru T, Tasci I, Ercin CN, Ozgurtas T, Erbil MK: Soluble CD40 ligand and soluble P-selectin levels in Gilbert's syndrome: A link to protection against atherosclerosis? Clin Biochem, 2009; 42: 791-795

44) Yang XF, Chen YZ, Su JL, Wang FY, Wang LX: Relationship between serum bilirubin and carotid atherosclerosis in hypertensive patients. Intern Med, 2009; 48: 1595-1599

45) Gonzalez MA, Selwyn AP: Endothelial function, inflammation, and prognosis in cardiovascular disease. Am J Med, 2003; 8: 115 Suppl 8A: 99S-106S

46) Andersson C, Weeke P, Fosbøl EL, Brendorp B, Køber L, Coutinho W, Sharma AM, Van Gaal L, Finer N, James WP, Caterson ID, Rode RA, Torp-Pedersen C; SCOUT Executive Steering Committee; SCOUT investigators: Acute effect of weight loss on levels of total bilirubin in obese, cardiovascular high-risk patients: an analysis from the lead-in period of the Sibutramine Cardiovascular Outcome trial. Metabolism, 2009; 58: 1109-1115

47) Melissas J, Malliaraki N, Papadakis JA, Taflampas P, Kampa M, Castanas E: Plasma antioxidant capacity in morbidly obese patients before and after weight loss. Obes Surg, 2006; 16: 314-320 